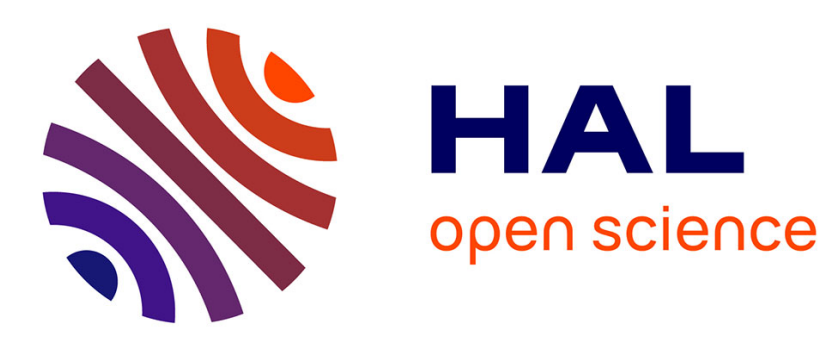

\title{
Generation of human-like motion on anthropomorphic systems using inverse dynamics.
}

Layale Saab, Philippe Souères, Nicolas Mansard, Jean-Yves Fourquet

\section{To cite this version:}

Layale Saab, Philippe Souères, Nicolas Mansard, Jean-Yves Fourquet. Generation of human-like motion on anthropomorphic systems using inverse dynamics.. Computer Methods in Biomechanics and Biomedical Engineering, 2012, 15 Suppl 1, pp.156-8. 10.1080/10255842.2012.713723 . hal-00764236

\section{HAL Id: hal-00764236 \\ https://hal.science/hal-00764236}

Submitted on 12 Dec 2012

HAL is a multi-disciplinary open access archive for the deposit and dissemination of scientific research documents, whether they are published or not. The documents may come from teaching and research institutions in France or abroad, or from public or private research centers.
L'archive ouverte pluridisciplinaire HAL, est destinée au dépôt et à la diffusion de documents scientifiques de niveau recherche, publiés ou non, émanant des établissements d'enseignement et de recherche français ou étrangers, des laboratoires publics ou privés. 


\title{
Generation of Human-like Motion on Anthropomorphic Systems using Inverse Dynamics
}

\author{
L. SAAB*† and P. SOUERES*† and N. MANSARD*† and J.Y. FOURQUET \\ †LAAS-CNRS, 7 avenue du Colonel Roche, 31077 Toulouse, France, Université de Toulouse (UPS) \\ $\ddagger$ LGP-ENIT, 47 avenue d'Azereix, 65016, Tarbes, France, Université de Toulouse (INPT)
}

Keywords: humanoid robot; whole-body movement; dynamics; stack of tasks; torque control

\section{Introduction}

This work deals with the generation of human-like whole-body movements on anthropomorphic systems. We propose a general framework to generate robot movements from the definition of ordered stack of tasks and a global resolution scheme that enables to consider different kinds of constraints [1]. We compare qualitatively the robot movements generated from this software with similar recorded human movements. We start with a direct global comparison of body movements. Then we analyze the magnitude of the reconstructed human torques and compare with the simulated robot torques during the motion.

\section{Humanoid motion generation and human movement analysis}

The motion generation method is based on the taskfunction formalism [4]. Complex movements are defined by a sequence of hierarchized stack of tasks [5]. Equality tasks are used to drive a task-function to a reference value, whereas inequality constraints enable to maintain functions of state variables above or below a given threshold. The degrees of freedom (DOF) of the robot are then simultaneously constrained to guarantee the execution of the highest priority tasks while satisfying at best the lower priority objectives. All along the movement the robot balance is ensured by specifc constraints. At each new phase of the movement the stack of task is restructured by introducing or cancelling tasks and by modifying their priority.

A global solver involving a cascade of Quadratic Programming problems [2, 3] is used compute the controller. A detailed presentation of this motion generation method is proposed in [1]. Note that this framework enables to take into account many possible rigid contacts between the robot and the environment during the movement. Furthermore, this method is generic and can be applied both to the kinematics and to the dynamics of the robot. In this work, we considered an extended model of the humanoid robot HRP-2.
The analysis of the human movement was done at the Yoshihiko Nakamura Lab. (YNL) of the University of Tokyo in collaboration with the LAAS-CNRS. We used a Motion Analysis motion capture device, EMG and force plates to record the movement of human subjects executing the same sequence of reaching movements. Based on these data, the software sDIMS, developed at the YNL, which includes a complete musculoskeletal (MS) model of the human body, was used to reconstruct the torques produced by the subject [6].

The human movement recordings and the robot motion generation were performed for the same reference movement. The subject was asked to execute a sequence of three reaching tasks with his right hand while balancing on its right foot. Additionally, he was holding a cup in his left hand and must maintain it around a fixed position. The first target was located on the ground in front of the subject. The second target was located at midheight on his right side, and the third one was behind him at shoulder level. Implicitly, during each reaching task the subject was required to look at the target. Four snapshots of the successive motion phases are shown in figure 1.

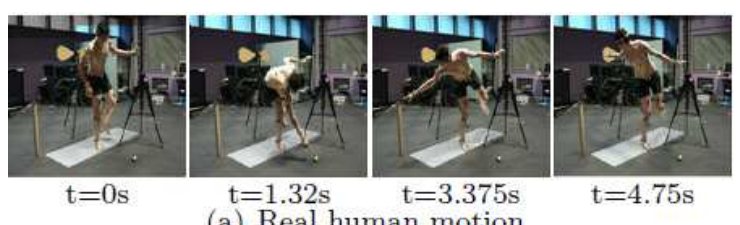

(a) Real human motion

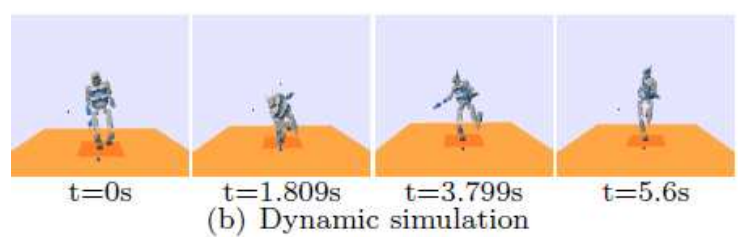

Figure 1: Snapshots of the motion of the human and the robot model

The main difficulty is to design the ordered stack of tasks to execute the expected sequence of reaching tasks. Figure 2 shows the chronology of the stack of tasks that was considered. The highest priority task ensures the robot balance by maintaining its center 
of mass (CoM) within the support polygon. Two inequality constraints are used to limit the variation of the left foot and the left hand position during the whole movement while their orientation are free. Three successive equality constraints are used to control the movement of the right hand toward each target. Equality tasks are also used to drive the gaze toward the current target. To avoid auto-collisions and to increase the resemblance to human movement, we also used equality tasks to drive the robot movement through two intermediary waypoints, IP1 and IP2, before reaching the targets. These points were selected as intermediary objectives because they appear to play a key role in the organization of the human motion.

\section{Results}

The human motion and the simulated robot movements were carefully analyzed. We first observed the global shape of movements and compared them. For this study we developed a specific robot model including 37 DOFs. This model is much less complex than the MS model, but the corresponding bodies have similar length, mass and inertia. We compared the magnitude of torques associated to the human and the robot movements. The effort distribution on the lower body joints and the torque trajectories of the upper body joints showed interesting similarities. For example, as shown in figure 3 , the joint torques exerted at the torso of the robot present the same shape and variation as the human torso torques. However, an important difference is observed and concerns the torque variation along the movement. Indeed, in the human motion, the torques vary rather smoothly whereas the robot torques trajectories present sudden peaks at the beginning of each phase of the movement. This is mainly due to the choice of the task dynamics in the sequencing of tasks. Indeed, to guarantee the convergence of each phase of the movement we imposed an exponential decay of the task-functions as it is usually done in robotics. This leads to a succession of exponential decays of torques with a high initial value at the beginning of each phase. To the contrary, despite the important change in the successive target positions, the human torques appear rather smooth, showing the importance of the anticipation process in human motor control.

\begin{tabular}{l|c|c|c|c|}
\hline COM & \multicolumn{4}{|c|}{ FIXED } \\
\hline LEFT HAND & \multicolumn{4}{|c|}{ BOLNDDED } \\
\hline LEFT FOOT & \multicolumn{4}{|c|}{ BOLNDED } \\
\hline RIGHT HANDIPI & FRONT TARGET & IP2 & RIGHT TARGET & BACK TARGET \\
\hline GAZE & FRONT & & RIGHT & BACK \\
\hline
\end{tabular}

Figure 2: Stack of tasks chronology with task priority decreasing from top to bottom
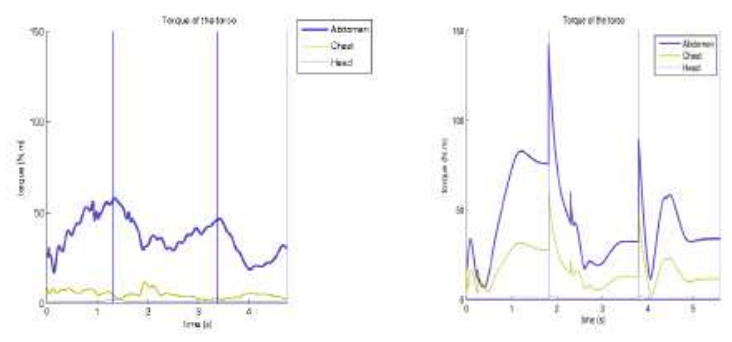

Figure 3: The torques variation of the robot and human torso

\section{Conclusion}

This study shows that our advanced motion generation software allows to generate complex movements resembling those of humans. The analysis of the reconstructed human movement and the simulated robot movement shows that the torque variation of the human movement is smoother. This important point suggests that the control design in the task space should be improved in order to take into account the dynamics of whole movement, instead of regulating each task individually.

\section{Acknowledgments}

The authors would like to thank Ko Ayusawa, Yosuke Ikegami and Manish Sreenivasa for making the experiments at the YNL.

\section{References}

[1] Saab L., Ramos O., Mansard N., Souères P., Fourquet J-Y., Generic Dynamic Motion Generation with Multiple Unilateral Constraints. IEEE/RSJ Int. Conf. on Intelligent Robots and Systems. San Francisco, USA, 2011.

[2] Fletcher R., A general quadratic programming algorithm. IMA Journal of Applied Mathematics, 7 (1971), 76-91.

[3] Escande A., Mansard N., Wieber P-B., Fast Resolution of Hierarchized Inverse Kinematics with Inequality constraints. IEEE Int. Conf. on Robotics and Automation. Anchorage, USA, 2010.

[4] Samson C., Le Borgne M., Espiau B., Robot Control: the Task Function Approach. Clarendon Press, Oxford, United Kingdom, 1991.

[5] Mansard N., Stasse O., Evrard P., Kheddar A., A Versatile Generalized Inverted Kinematics Implementation for Collaborative Working Humanoid Robots: The Stack of Tasks. 119 Int. Conf. on Advanced Robotics. Munich, Germany, 2009.

[6] Nakamura Y., Yamane K., Fujita Y., Suzuki I., Somatosensory computation for man-machine interface from motion-capture data and musculoskeletal human model. IEEE Transaction on Robotics 21(2005), 58 - 66. 